www.nature.com/pj

\title{
EDITORIAL
}

\section{Plans for 2012}

\author{
Polymer Journal (2012) 44, 1; doi:10.1038/pj.2011.131
}

$\mathrm{T}$ his is the start of the 3rd year of Polymer Journal (PJ)'s publishing partnership between the Society of Polymer Science, Japan (SPSJ) and Nature Publishing Group (NPG). I am pleased to see that the foundation that was built in 2009 through this relationship remains strong and the new innovative advances have seen PJ gaining further recognition within the international polymer community.

I would like to sincerely thank all the authors, readers and subscribers. Of course, the present success would not have been possible without the continued, strong support of our Editorial Board members, Associate Editors and Editorial Office staff. I would like to thank all my colleagues on the Editorial Board and in the PJ editorial office.

In 2012, the Society of Polymer Science, Japan, will celebrate its 60th anniversary. All the issues published in 2012 (Vol. 44) will commemorate this occasion by decorating the front covers with the 60th anniversary logo and banner, and including specially designed content. First, I am pleased to present this January issue as a special issue featuring Dr Ichiro Sakurada, who is known as a founder of 'polymer science' in Japan with many valuable achievements in the study of both the synthesis and properties of polymers. In addition to the collection of reviews by outstanding researchers in current polymer studies, English translations of Sakurada's original papers are reproduced as 'Memorial Papers'. I am sure that this January special issue, including many review articles on the most progressive scientific results and important concepts, will be well worth a read.
Second, we will be publishing a series of specially contributed review articles by the previous recipients of the SPSJ International Award during this anniversary year. We are aiming to publish the first special contribution in the February issue. Finally, we have another special issue planned for the middle of the year. This will be an issue featuring self-organizing materials, with two invited guest editors.

We are hoping that these special features will help bring more readers and authors to PJ to further solidify the firm base for further growth.

Most likely as a result of the effort to make PJ better known, more visible and easier to find on the borderless internet, we now have a higher proportion of papers submitted from outside of Japan. My fellow editorial board members and I are committed to keep working hard to make every effort to satisfy the readers, to develop PJ as a prominent international research arena and active platform for communication, and thus contribute to the progress of polymer science. I thank all those helping PJ, such as our authors, readers and reviewers, for your continued support and interest, and wish you all a very Happy New Year on behalf of the PJ team.

Toshikazu Takata Editor-in-Chief Polymer Journal 